\title{
Research on Digital Skills that Accountants Should Possess in the Intelligent Era
}

\author{
Yaoteng Zhao \\ School of Business, Liaocheng University, Liao Cheng 252000, Shandong, China \\ Email: zytcpa@163.com
}

\begin{abstract}
The intelligent era is also known as the fourth industrial revolution. One of the features of the intelligent era is that people use digital technologies such as artificial intelligence, block chain, 5G, cloud computing and mobile animal networking to carry out production, operation and management activities. At present, digital technology is an important factor in promoting social and economic development around the world. Representative digital technology gradually empowers the fields of financial accounting, management accounting, corporate financial management, audit and corporate governance. In this paper, we study and discuss the digital technology that a qualified accountant should possess in the intelligent era, which also provides a directional guidance for the training of intelligent accounting talents in the future.
\end{abstract}

Keywords: intelligent era, accountant, digital technology

\section{Introduction}

Big data is characterized by huge amount of data, complex structure, fast growth rate and low value density. Big data's own characteristics also make his processing methods complex and difficult to analyze. The emergence of big data not only brings people to deal with challenges, but also provides the possibility of comprehensive, accurate and profound understanding and handling of problems. The evolution of data is a continuous and gradual process, and the shape and structure of data are constantly upgraded and iterated. Data can be divided into three forms, namely, primary data, scientific data and big data. In big data's era, data has become a social resource similar to oil, natural gas and electricity, and companies have valuable assets when they have economic data.

Digital technology provides a historic opportunity for national business development, which helps to change the mode of production and greatly improve production efficiency, and then change the deep-seated problems of the mode of economic development. In terms of expanding domestic demand in the domestic market, digital technology will help build smart cities and villages and closely link the relationship between enterprises and consumers, so as to optimize product quality and develop new consumer demand. The security and confidentiality of data in the field of accounting are the key issues of continuous concern. Users' data is stored in the service provider's memory, and only when customers' concerns about information security are completely dispelled, cloud computing services can develop smoothly. Cloud computing service providers need to ensure that the access behavior of customers' data information must be properly authorized, and the password length and complexity can be managed mainly through symmetric and asymmetric encryption algorithms.

\section{Digital management}

A broad definition of digital management is the use of digital technology in production and management activities. Digital management is the basis for enterprises to achieve intelligent management, digital management has the following characteristics. First, the business process is digitized. For example, digital operation is needed in the production planning, procurement, production, marketing and logistics of manufacturing enterprises. In the aspect of customer demand forecasting and analysis, digital operation can enable enterprises to obtain more kinds and quantity of information than under the original traditional business model, such as customers browsing product labels and residence time in corporate web pages or mobile phone software. The shopping information left by customers subconsciously has become the direct embodiment of their consumption preferences and personalized needs. Enterprise managers can more accurately analyze the real needs of customers by using more mature data analysis methods. In the aspect of product design, digital technology first obtains the information of market consumption trend from customer purchase and commodity sales. In addition, digital analog, VR and AR technologies also play an auxiliary role in many aspects. For example, virtual reality technology enables customers to truly feel the appearance, size and usage of products at home, which eliminates the obstacles of shopping and browsing in space and provides customers with great convenience. Meanwhile, the emergence of smart wearable products can enable 
businesses to obtain customers' usage habits and feelings more comprehensively, more accurately and at a low cost, and these Internet of things products can also establish an interactive bridge between merchants and consumers. customers can feedback the new needs of their feelings in real time, and businesses can optimize and upgrade their products in a more timely manner. Figure 1 shows the roadmap of digital operation for empowering enterprises.

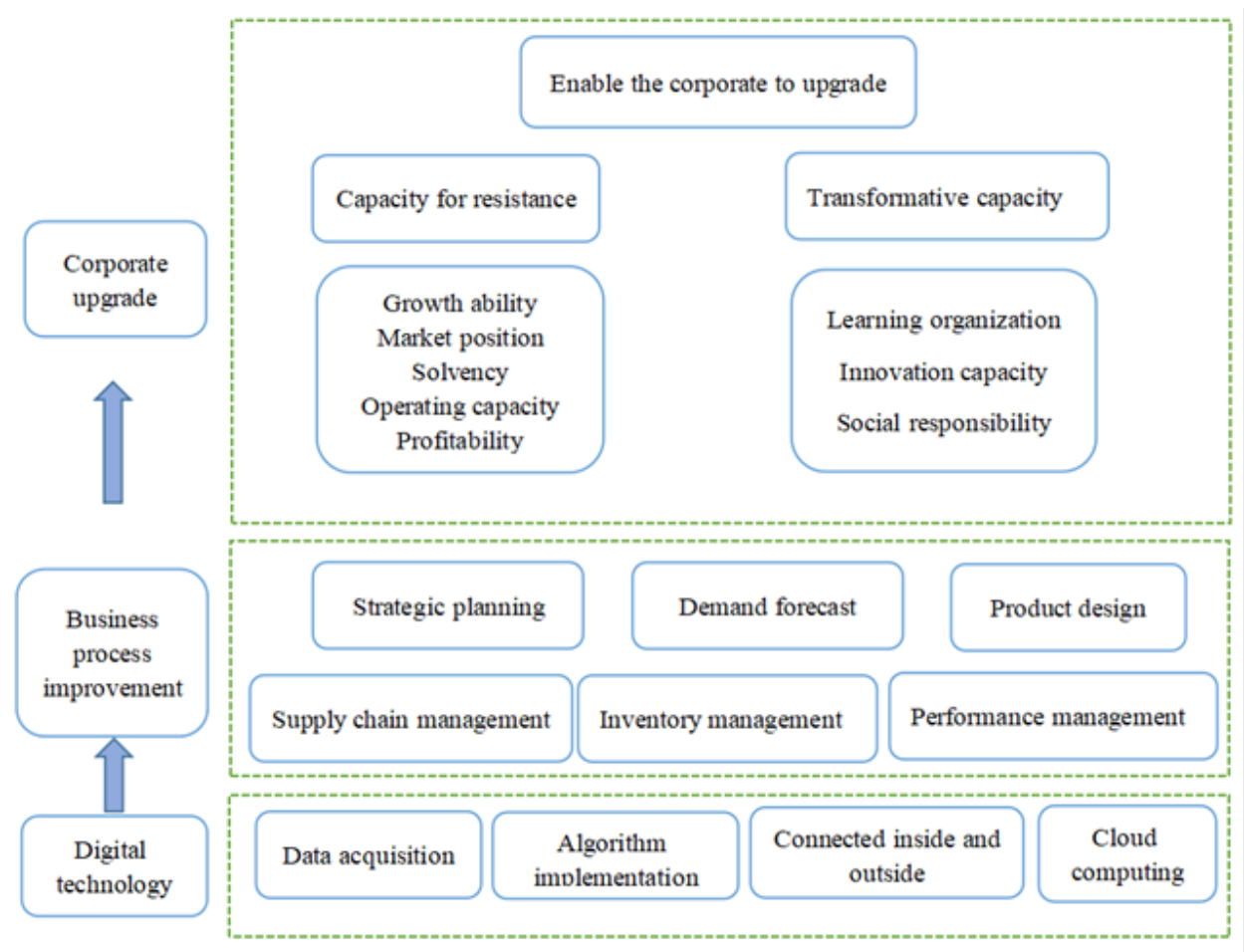

Figure 1. Digital technology enable the corporate to upgrade

\section{Artificial intelligence}

Artificial intelligence technology is profoundly changing various industries in economic life, among which the field of accounting will be affected more profoundly. Accounting and financial management itself is intelligence-intensive work, including low professional ability requirements of the flow of work, but also requires high professional judgment of decisionmaking management work. The former is the hardest hit by artificial intelligence technology, and the related jobs are rapidly disappearing, while the staff in the latter position will not be completely replaced at present, but they must also have a sense of crisis and need to make artificial intelligence technology available to me. The field of combining artificial intelligence technology with financial management activities can be called intelligent finance, which has not yet been uniformly defined, but the related changes are surging. If accounting computerization has caused the first change in the financial field, then financial sharing is the second change in the financial field, and the financial work in the intelligent era will usher in the third change. This change will be affected by artificial intelligence technology and cloud computing services, which can be called "intelligent cloud finance" revolution. It is generally believed that the products provided by cloud service companies can be divided into three categories, namely IaaS (Infrastructure-as-a-Service), PaaS(Platform-as-a-Service) and SaaS (Softwareas-a-Service).

Corresponding changes will take place in the financial organization in the intelligent era, and the new organization will be fully integrated and coordinated with artificial intelligence technology, big data, cloud computing and block chain. The new financial organization structure needs a data operation team for the acquisition, storage and maintenance of financial data, as well as a professional team that can use big data and artificial intelligence technology for financial modeling, risk management and intelligent budget. The machine learning algorithm can automatically identify and transform the previously difficult unstructured data into structured data, which can make the scope of information analysis more comprehensive, and then use the machine learning algorithm to find the factors that affect the financial risk of the company. However, at this time, the algorithm only finds the relevance and potential rules, and can not know the connection logic. If you want to further explore the inherent logic, you need professional financial personnel to carry out targeted analysis. Artificial intelligence, big data and cloud computing technology are even more promising in the field of enterprise budget management. The financial 
budget is analyzed and predicted based on historical data, combined with the changing trend of popular products in the market and the development of competitors in the same industry, so as to achieve a more scientific and reasonable allocation of resources.

\section{Blockchain}

The essence of blockchain technology is decentralized distributed bookkeeping, which is doomed to have a huge chemical reaction with accounting from the date of its birth, and has the potential to subvert the way of accounting work. The characteristics of blockchain technology are open and transparent, distributed and decentralized. It is expected to greatly improve the working mode and efficiency by using the characteristics of blockchain in the field of accounting. The bookkeeping method based on blockchain technology is not controlled by one subject, but controlled and saved by multiple trading parties, so all trading parties have the same record authority, thus forming a flat organizational structure.

The distributed accounting mode enables the trading side to record the same trading information, even if one party tampers with the information recorded by itself, because other trading parties still record accurate information, which can not change the facts. Although a subject with super computing power in theory has the possibility of tampering with information, this possibility can be ignored in practice. Different blocks are linked by hash value to form an overall chain structure, so the information recorded by block chain technology can be traced back to the source. Besides, because the block chain has a time stamp function, each record has a time label, and the irreversible time label further increases the technical difficulty of tampering and fabricating information.

Additionally, the blockchain technology is expected to significantly improve the audit efficiency, and the national audit institutions are expected to establish a real-time supervision system by using the blockchain technology. The broadcast mechanism of information recording can improve the credibility of the audit system, and the use of intelligent contract technology can individualize the transaction conditions, such as setting the direction of the use of certain funds and achieving the supervision of special funds in advance. The time stamp function with irreversible characteristics is expected to significantly reduce the risk of financial fraud and material misstatement. Moreover, the problems of data capacity and supervision cost in traditional audit work are more serious, the method of using block chain distributed data storage can get rid of the constraints of building a central server, so as to greatly reduce audit costs, save resources and improve economic benefits. In the context of using digital technology for audit work, auditors use digital technology to clean and organize data and refine financial data with low value density into high-quality audit clues. As a result, the tedious and complex data collection work at the bottom can be greatly reduced, and most of the time and energy will be devoted to the advanced audit work, and finally achieve the effect of improving the audit quality.

\section{Data mining and visualization}

Business data records the whole process of enterprise operation. Accountants must master data mining skills in the face of massive business data. Using data mining technology accountants can explore the internal operation law of the enterprise, grasp the business development trend, provide a valuable reference basis for business decision-making, and finally achieve the purpose of creating value. Data mining is to find the inherent hidden logic and relations from a large number of multistructured data, and use these findings to establish a scientific quantitative model, and use a variety of analysis tools to get predictive decision planning.

Data mining can help to change the enterprise's intelligent business process from a chain to a circular closed loop. The beginning of the intelligent business closed loop is the business system of the enterprise, which produces the original business data, which provides the material for the data mining work. The second link is data integration, which collects, collates and classifies the data related to enterprise management. The third link is to store the data in the database to accumulate and save the data. The fourth link is to compile data reports to observe and understand the operation of the enterprise from a shallow level. The fifth link is the core link, that is, data mining, in-depth understanding of the nature of business operation, the use of a variety of data analysis methods to get the best business decision. The last link is the enterprise optimization link, which adjusts and optimizes the business links, organizational structure and marketing strategies according to the business decisions obtained by data mining and analysis, so as to improve the business efficiency and market competitiveness.

An important application of data mining in the industrial field is the construction of the industrial Internet of things. Industrial Internet is essentially a set of enterprise operation control and service system based on the collection, analysis, processing and decision support of massive data in the industrial chain. Connecting network is the infrastructure, which connects staff, raw materials, workshop equipment, products, dealers and suppliers, etc., and opens up internal and external procurement, research and development, production, operation, sales and transportation. The security system provides 
guarantee for the whole industrial Internet system, and the security contents include data information security, hardware and software equipment security, network transmission security, technology research and development security and public relations public opinion. The industrial Internet connects resources, data and people, which will be a deep combination of advanced data analysis and computing, sensing technology, the Internet and industrial systems. The development of industrial Internet is inseparable from the interconnection of business process management and on-site operation management, that is, the integration and docking of ERP (Enterprise Resource Management Plan) and MES (Manufacturing execution system). Financial cloud ERP based on SaaS model can achieve cross-enterprise, cross-platform and cross-device interconnection, open up the upstream and downstream industry chain resource allocation planning, and deal with industrial-level data processing. The three constituent elements of industrial Internet are data platform, connecting network and security system, among which data platform is the core.

\section{Conclusion}

Due to the characteristics of the research content in the field of accounting, digital technology has a broad space to develop. The research characteristics in the field of accounting are usually as follows: first, the research is mainly based on historical data. At present, accounting research data also show the characteristics of wide distribution and explosive growth. With the support of the development of computer, Internet, big data, etc, artificial intelligence theory and algorithm has the advantages of collecting, processing and analyzing financial data. At the same time, it also improves the scientific, normative and reliable nature of the research; second, accounting decisions follow certain laws or standards. The study of accounting usually discovers and explores the laws contained in accounting and financial activities in historical data, and then scholars put forward research conclusions and professionals must follow certain standards when making financial decisions. These research conclusions and decision-making standards usually need to be supported by quantitative and mathematical derivation, otherwise they can not reflect the basic principle of rigor in scientific research. Since accounting research conclusions and decision-making standards can be quantified, most of the analysis, processing, summary and prediction work can be handed over to the financial robot with artificial intelligence algorithm. However, it is worth noting that it requires professional financial researchers to carry out the necessary supervision and adjustment.

\section{References}

[1] Daniel, E, O'Leary. AI in Accounting, Finance and Management[J]. Intelligent Systems in Accounting, Finance and Management, 2014, 4(3):149-153.

[2] $\mathrm{Ng} \mathrm{C}$, Alarcon J. Applications of AI in Accounting[M]. 2020.

[3] Leitner-Hanetseder S, Lehner O M, Eisl C, et al. A profession in transition: actors, tasks and roles in AI-based accounting[J]. Journal of Applied Accounting Research, 2021, ahead-of-print(ahead-of-print).

[4] H Fu. AI-related Challenges for Accounting Work and Reform for Talent Training[J]. Journal of Guilin Normal College, 2019.

[5] Shu-Qian F U, Wen-Bin Y U, Zheng R, et al. Specific Application of AI Technology in the Accounting Industry[J]. Value Engineering, 2019.

[6] Zhao Y, Chupradit S, Hassan M, et al. The role of technical efficiency, market competition and risk in the banking performance in G20 countries[J]. Business Process Management Journal, 2021.https://doi.org/10.1108/BPMJ-12-20200570 .

[7] Zhao M F. Study on Smart Accounting Teaching Model Composed of Information Technology and Teaching System under Background of 'Internet+' Initiative[J]. Journal of Qiqihar Junior Teachers' College, 2017.

[8] Dwyer, Dori. Intelligent Accounting[J]. Insurance \& Technology, 2008.

[9] Wang T, Yang L. Design and implementation of intelligent accounting data analysis platform based on industrial cloud computing[J]. EURASIP Journal on Wireless Communications and Networking, 2020, 2020(1).

[10] Yuanlue F U. Intelligent Accounting: Financial Robots and Accounting Reform[J]. Journal of Liaoning University (Philosophy and Social Sciences Edition), 2019.

[11] Zhao Y, Li X. Research on green innovation countermeasures of supporting the circular economy to green finance under big data[J]. Journal of Enterprise Information Management, 2021. https://doi.org/10.1108/JEIM-01-2021-0039.

[12] Gillett P R. What can AI offer the accounting profession?[C]/Strategic Industrial Issues in AI in Engineering, IEE Colloquium on. IET, 2002. 